Research Article

\title{
Potential Analysis of High-g Shock Experiment Technology for Heavy Specimens Based on Air Cannon
}

\author{
Zhengyong Duan $\mathbb{D}^{1,},{ }^{1,2}$ Tianhong Luo $\mathbb{D}^{2},{ }^{2}$ and Dayong Tang ${ }^{2}$ \\ ${ }^{1}$ The State Key Laboratory of Mechanical Transmissions, Chongqing University, Chongqing, China \\ ${ }^{2}$ Chongqing University of Arts and Sciences, Chongqing, China \\ Correspondence should be addressed to Tianhong Luo; 63077600@qq.com
}

Received 21 November 2019; Revised 10 October 2020; Accepted 16 October 2020; Published 26 November 2020

Academic Editor: Rozaimi Ghazali

Copyright (c) 2020 Zhengyong Duan et al. This is an open access article distributed under the Creative Commons Attribution License, which permits unrestricted use, distribution, and reproduction in any medium, provided the original work is properly cited.

\begin{abstract}
According to the technical requirements of harsh shock environment test, this paper presents the study on the pneumatic vertical test technology with large load and high-g value. The inspiration of this paper comes from the fact that a compressed air cannon can produce instantaneous and powerful air jets that can be used to drive the tested object to achieve a high initial collision velocity. Then, the principle of shock test technology based on an air cannon and an impact cylinder was put forward, and the idea gas mechanics model was established to theoretically analyze the laws that how the parameters of the air cannon and cylinder influence the initial impact velocities. The test system was built, and the test research was carried out. When the air cannon pressure is $0.5 \mathrm{MPa}$ and $0.65 \mathrm{MPa}$, respectively, under no-load, the impact acceleration measured is $1990 \mathrm{~g}$ (pulse width, $1.26 \mathrm{~ms})\left(1 \mathrm{~g}=9.8 \mathrm{~m} / \mathrm{s}^{2}\right)$ and $4429 \mathrm{~g}$ (pulse width, $\left.1.20 \mathrm{~ms}\right)$. It preliminarily validated the effectiveness and feasibility.
\end{abstract}

\section{Introduction}

Air cannon is a kind of declogging device which can produce high pressure air jet by instantly releasing the compressed air deposited in a vessel. When the ratio of the vessel's internal and external pressure is excess of 1.89 , the air jet velocity is up to the velocity of sound. So, if the air jet encounters some obstacles, there will be a great impulse force on the objects. Therefore, air cannons are widely used in the transport pipes of warehouses, docks, furnaces, and coal mines to prevent bond and assist flow [1].

It is known that the energy released by an air cannon is great and concerned with its volume and pressure of the compressed air. For example, the energy released by an air cannon is excess of $40000 \mathrm{~J}$ for the pressure of $0.6 \mathrm{MPa}$ and volume of 50 liters. In some cases, an air cannon can not only be used to simulate high-g shock environments but also be utilized as an excitation source in shock tests. It is also known that high-g value shocks usually appear in these events such as the separation of rocket booster, explosive impact on military tank structures, or metal-to-metal impact. Such parts or systems working in the harsh inertial environments must strictly test for design qualification, survivability testing, and calibration. For specimens with variable weights and sizes, now available experimental technologies include pendulum striker, drop machines, Hopkinson pressure bar, free fall drop test devices, air gun, rail gun, explosion near field simulation, and warhead penetration [2-12].

The inspiration of this paper comes from the fact that a compressed air cannon can produce instantaneous and powerful air jets that can be used to drive the tested object to achieve a high initial collision velocity. An idea gas mechanics model was established for the driving system to theoretically analyze the rules that how the parameters of air cannon and cylinder modulate the initial impact velocities. Also, a test system was built, and the test research was carried out. Some experiments were carried out and obtained typical half-sine shock pulses in the case of no-tested specimens. The test results preliminarily validated the effectiveness and feasibility of the technical solution. 


\section{Technical Principles}

Except for the Hopkinson pressure bar device which is based on the one-dimensional stress wave principle to produce high-g shock environments, the rest are based on the collision principle to produce a required high-g shock test environment. Inspired by the air cannon and impact cylinder technology, this paper comes up with the technical solution for such specimens with heavy weight and large size. The schematic diagram of the shock machine is shown in Figure 1.

The carriage is a rigid, cast aluminum table with steelthreaded inserts for mounting the tested specimen. The air cannon is filled with high pressure air. It can produce high pressure air flow that enters the cylinder through the " $Y$ " inlet elbow to push the piston assembly (including the guide rod, impact plate, and carriage) downward to achieve a certain velocity prior to impact. The anvil is an impactresistance iron that is attached to the top of the case. A pulse shaper can be set on the anvil to get an expected shock pulse. The height setting mechanism can not only provide a means of establishing proper height but also play as a limit switch when the piston assembly is lifted. The pneumatic braking system can keep the piston assembly at a setting height and release it immediately after the air cannon sprays the air flow. The time delay between the generation of the gas flow and the release of the piston assembly can be obtained through equipment commissioning. The isolation gasbag system is designed for minimum load transmissibility to the immediate floor and surrounding area during impact and provides a support for the other parts.

For those peer experts, it can be seen that this technical solution is similar to the AVEX Shock Machine technology [13]. But there is a markedly innovation that an independent air cannon is intentionally used in the driving system. Just owing to this point, there will be some significant advantages listed as follows:

(1) The sealing conditions of the piston and cylinder are no longer harsh and even do not need to pay special attention to the sealing problems. So, the friction of the cylinder-piston pair can be reduced greatly. Therefore, the energy released by the air cannon can be more transformed to the speed of the piston assembly.

(2) The braking system is easier to achieve. From Figure 1 , it can be seen that there is no high pressure air acting on the topside of the piston before the air cannon producing an air flow. Therefore, the brake system only needs to support the gravity of the piston assembly.

(3) It is easier to change the driving force by installing different volume air cannons and changing the air pressure. Therefore, this technology can be used in a wider range of high-g shock experiments.

\section{Gas Mechanics Model and Analysis}

The key point is how to obtain a high impact initial velocity for those high-g shock experiment technologies based on the

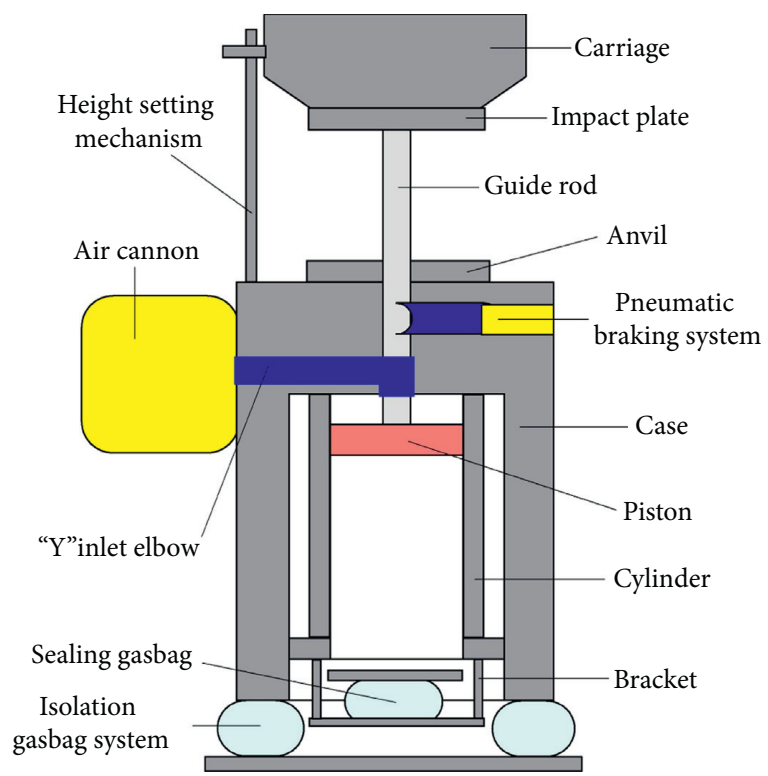

FIgURE 1: Schematic diagram of the shock machine.

collision principle. According to Figure 1, an ideal gas mechanics model as shown in Figure 2 is established for theoretical analysis.

In Figure 2, $P_{0}$ is the back pressure acting on the lower surface of the piston. Here, it is equal to the atmospheric pressure; $P_{1}$ and $V_{1}$ are the pressure and volume of the air cannon; $P_{2}$ and $V_{2}$ are the pressure and volume of the final space occupied by the released air; $L_{0}$ is the reserved gap of the cylinder, and $L$ is the stroke of the piston; $d_{1}, d_{2}$, and $d_{3}$ denote the diameters of the "Y" inlet elbow, guide rod, and piston (cylinder), respectively; $x(t)$ denotes the displacement of the piston.

Because the velocity of the high pressure air flow released from the air cannon can reach the velocity of sound, the time from the generation of air flow to the occurrence of collision is very short. Therefore, this process can be taken as an ideal gas adiabatic expansion process, and the released energy $W$ can be given by [5]

$$
W=\frac{P_{1} V_{1}}{k-1}\left[1-\left(\frac{V_{1}}{V_{2}}\right)^{k-1}\right],
$$

where $k$ is the adiabatic index of gas, $k=1.4$ for air.

When taking account to the rate of energy loss $\eta$ during this process and ignoring the total weights of the piston assembly and tested specimen, the initial impact velocity $v_{0}$ is can be written as follows according to the principle of conservation of energy:

$$
v_{0}=\sqrt{\frac{2 P_{1} V_{1}(1-\eta)}{m(k-1)}\left[1-\left(\frac{V_{1}}{V_{2}}\right)^{k-1}\right]} \text {, }
$$

where $m$ is the total masses of the moving parts.

It is noted that $V_{2}$ can be determined by

$$
V_{2}=V_{1}+l A_{1}+\left(L+L_{0}\right)\left(A_{3}-A_{2}\right),
$$




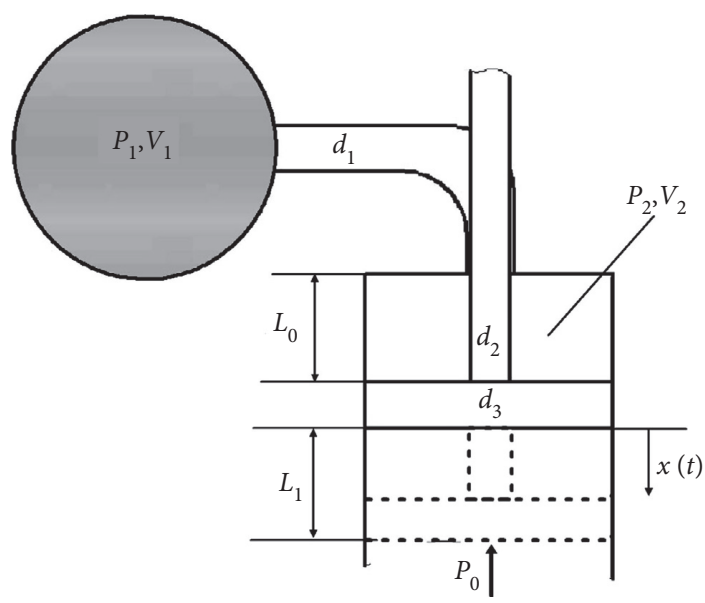

Figure 2: The ideal gas mechanics model of the driving system.

where $l$ is the effective length of the "Y" inlet elbow, and $A_{1}$, $A_{2}$, and $A_{3}$ are given as

$$
\begin{aligned}
& A_{1}=\frac{\pi}{4} d_{1}^{2}, \\
& A_{2}=\frac{\pi}{4} d_{2}^{2}, \\
& A_{3}=\frac{\pi}{4} d_{3}^{2},
\end{aligned}
$$

respectively.

But the movement of the moving parts is a dynamic process. So, a dynamic equilibrium equation is established according Newton's second law without considering the effect of damping:

$$
P_{2} V_{2}\left(A_{3}-A_{2}\right)+m g-P_{0} A_{3}=m \ddot{x}(t),
$$

where the initial conditions are

$$
\begin{aligned}
& x(t=0)=0, \\
& \dot{x}(t=0)=0 .
\end{aligned}
$$

According to equation (3), $v_{2}$ in equation (5) is easily evolved to the form as follows:

$$
V_{2}=V_{1}+l A_{1}+\left[x(t)+L_{0}\right]\left(A_{3}-A_{2}\right) .
$$

Furthermore, equation (7) is equivalent to the following form:

$$
V_{2}=\left[L_{0}^{\prime}+x(t)\right]\left(A_{3}-A_{2}\right),
$$

where $L_{0}^{\prime}$ is the equivalent cylinder gap and the equivalence principle is

$$
L_{0}^{\prime}\left(A_{3}-A_{2}\right)=V_{1}+l A_{1}+L_{0}\left(A_{3}-A_{2}\right) .
$$

Similarly, the process of air cannon producing an air flow can be taken as an ideal gas adiabatic expansion process. Therefore,

$$
P_{1} V_{1}^{k}=P_{2} V_{2}^{k}
$$

Synthesizing equations (4), (7), (8), and (10), it is deduced that

$$
\frac{\mathrm{d}^{2} x(t)}{\mathrm{d} t^{2}}=\frac{A}{m}\left[L_{0}^{\prime}+x(t)\right]^{-k}+\frac{B}{m},
$$

where

$$
\begin{aligned}
A & =P_{1} V_{1}^{k}\left(A_{3}-A_{2}\right)^{1-k}, \\
B & =m g-P_{0} A_{3} .
\end{aligned}
$$

By solving differential equation (11), we can therefore get that the initial impact velocity of the moving parts is

$$
v_{0}=\sqrt{\frac{2 A L_{0}^{\prime}(1-k)}{m(1-k)}\left\{\left[1+\frac{x(t)}{L_{0}^{\prime}}\right]^{1-k}-1\right\}+\frac{2 B}{m} x(t) .}
$$

In order to analytically find out that how the key parameters influence the initial impact velocities, some calculations and analysis are performed hereafter for the given relatively fixed parameters of $d_{1}=67 \mathrm{~mm}, d_{2}=60 \mathrm{~mm}$, and $\eta=0.2$.

First of all, we start from the cylinder diameter with a scope of $160 \mathrm{~mm}$ to $320 \mathrm{~mm}$. The qualitative curves of $v_{0}$ versus various values of $d_{3}$ are shown in Figure 3 based on equations (2) and (13) for the given parameters of $m=150 \mathrm{~kg}, \quad p_{1}=0.8 \mathrm{MPa}, \quad V_{1}=50 \mathrm{~L}, \quad L=400 \mathrm{~mm}$, and $L_{0}=0 \mathrm{~mm}$.

It can be seen that the initial impact velocities are approximately linearly increasing with the cylinder diameters within the interesting scope for given conditions. The results calculated by equation (2) are greater than the corresponding ones by equation (13). This is helpful to finding out a proper cylinder diameter.

Secondly, we take account for variable values of pressure and volume of the air cannon. The scopes are $0.4 \mathrm{MPa}$ to $0.8 \mathrm{MPa}$ and $30 \mathrm{~L}$ to $70 \mathrm{~L}$, respectively. And the other fixed parameters are $m=150 \mathrm{~kg}, L=400 \mathrm{~mm}$, and $L_{0}=0 \mathrm{~mm}$. In terms of equations (2) and (13), the curves of $v_{0}-p_{1}$ are shown in Figure 4(a), and $v_{0}-p_{1}$ curves are shown in Figure 4(b). It is clear that the initial impact velocities also exhibit approximately positive linear relationship with the pressure and volume of the air cannon. But in order to obtain a higher initial impact velocity, it is much more effective by increasing the pressure rather than the volume of the air cannon. Similarly, this can help us to design the reasonable air cannon parameters.

The third turns to the piston stroke and reserved gap. It is equivalently a dynamic process for different volumes of $L$. So, here, we utilize equation (13) to calculate for given parameters of $P_{1}=0.8 \mathrm{MPa}, V_{1}=50 \mathrm{~L}, d_{3}=240 \mathrm{~mm}$, and $m=150 \mathrm{~kg}$. And $L$ ranges from $50 \mathrm{~mm}$ to $500 \mathrm{~mm}$ and $L_{0}=0 \mathrm{~mm}, 100 \mathrm{~mm}, 200 \mathrm{~mm}, 300 \mathrm{~mm}$, and $400 \mathrm{~mm}$, respectively. The $v_{0}-L$ curves are presented in Figure 5.

From Figure 5, it can be seen that it is not necessary to design a reserved gap. This is also good for reducing the device height. On the other hand, in order to get a high expected initial impact velocity, not less than $300 \mathrm{~mm}$ stroke is quite necessary. 


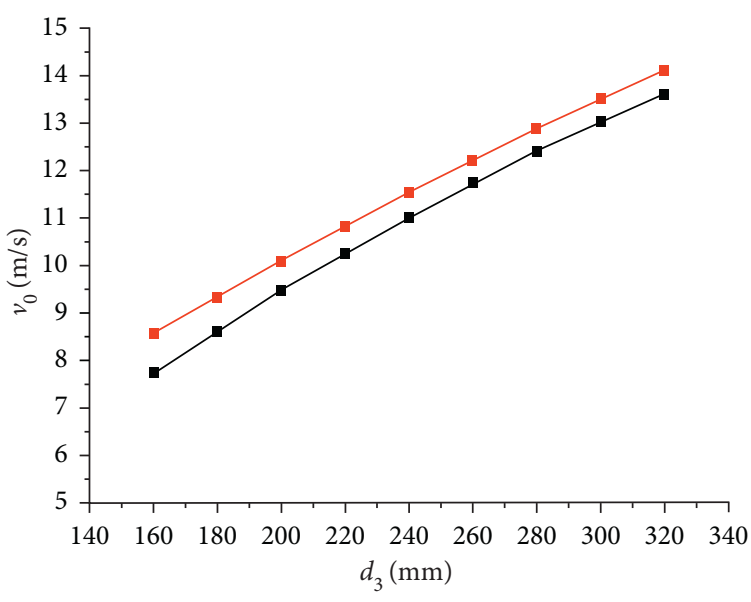

$\rightarrow$ by eq.(13)

- by eq.(2)

Figure 3: The curves of $v_{0}-d_{3}$.
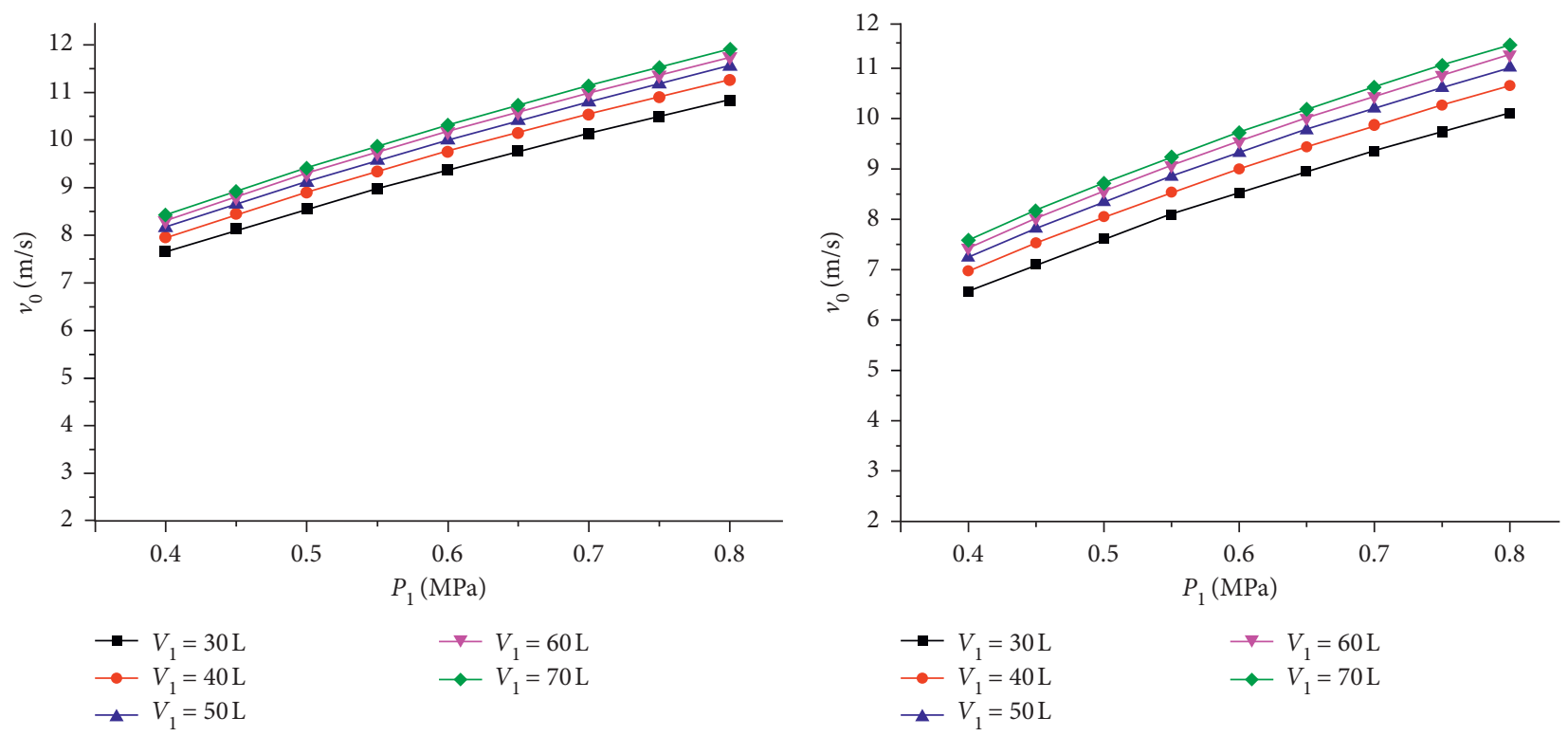

(a)

FIgURE 4: Continued. 

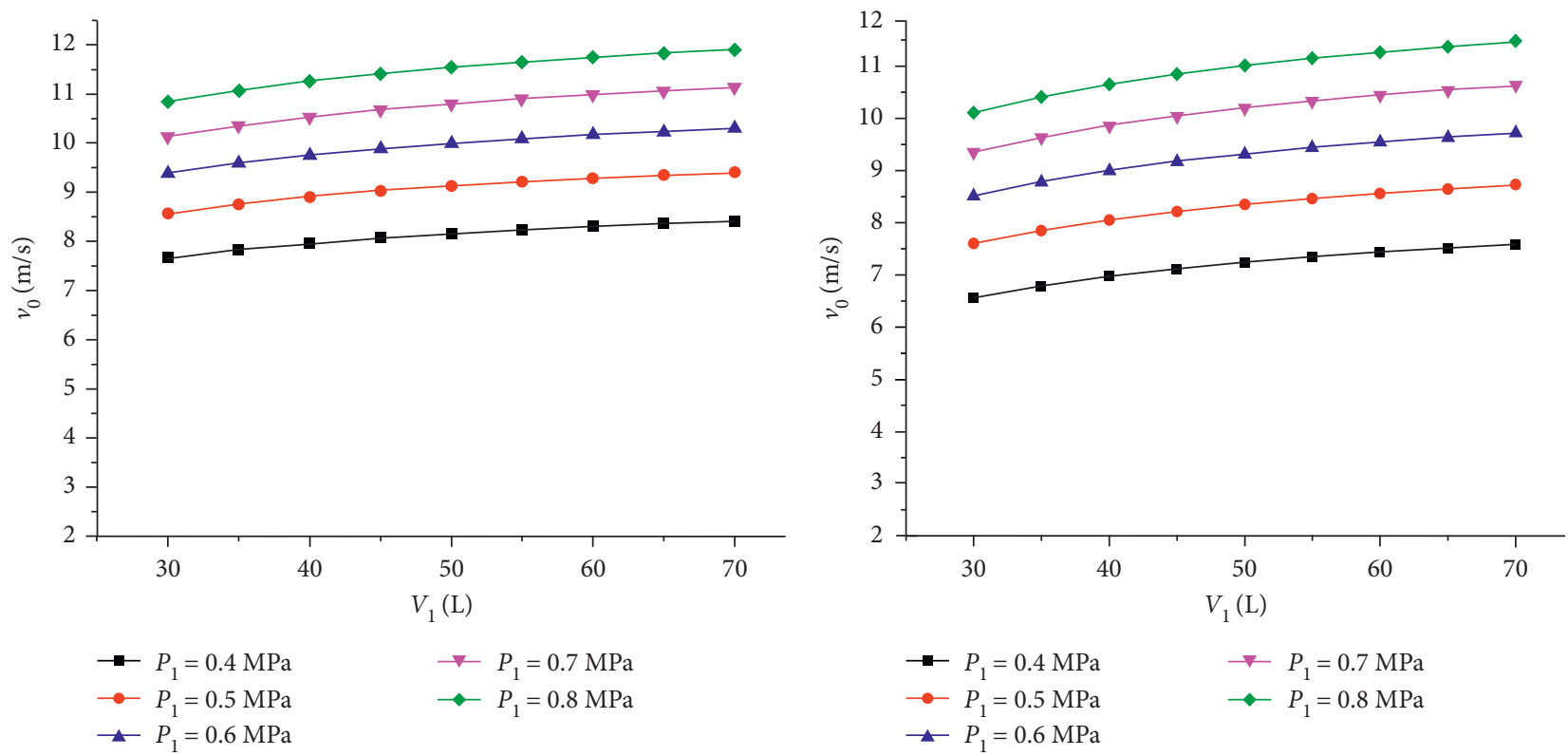

(b)

FIgURE 4: Theoretic curves of initial impact velocities versus reassures and volumes of air cannon. (a) The curves of $v_{0}-p_{1}$ (by equations (2) and (13)). (b) The curves of $v_{0}-V_{1}$ (by equations (2) and (13)).

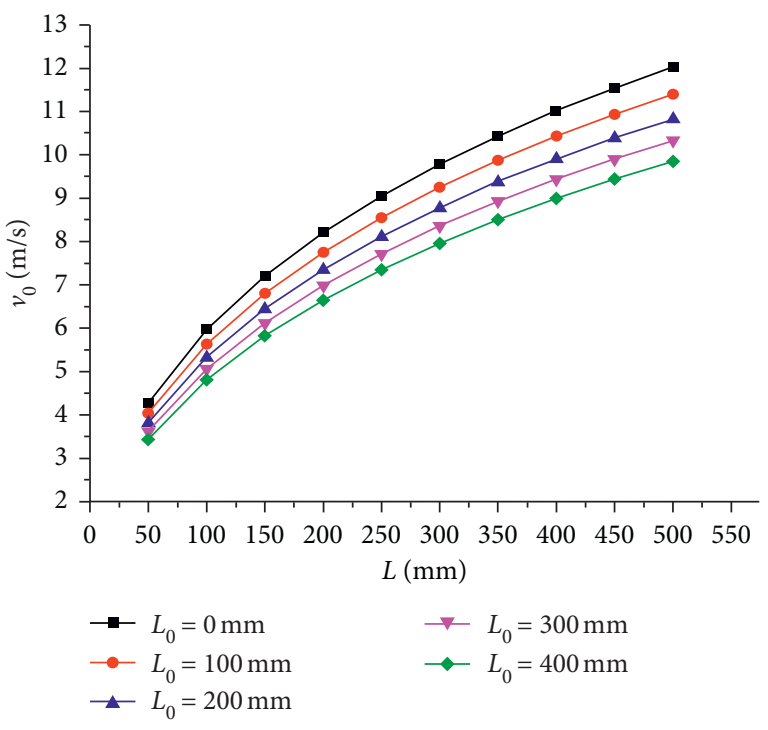

FIgURE 5: Theoretic curves of $v_{0}-L$.

Finally, the total masses of all moving parts are taken into account since this will determine the device payload capacity. Here, the fixed parameters are $P_{1}=0.8 \mathrm{MPa}$, $V_{1}=50 \mathrm{~L}, d_{3}=240 \mathrm{~mm}, L=400 \mathrm{~mm}$, and $L_{0}=0 \mathrm{~mm}$, and $m$ ranges from $50 \mathrm{~kg}$ to $600 \mathrm{~kg}$. The $v_{0}-m$ curves are shown in Figure 6.

It is clear that the initial impact velocity drops rapidly with the increase of $m$. But for $m=600 \mathrm{~kg}$, the initial impact velocity is still in excess of $5 \mathrm{~m} / \mathrm{s}$. It means that the payload capacity is good for these configurations.

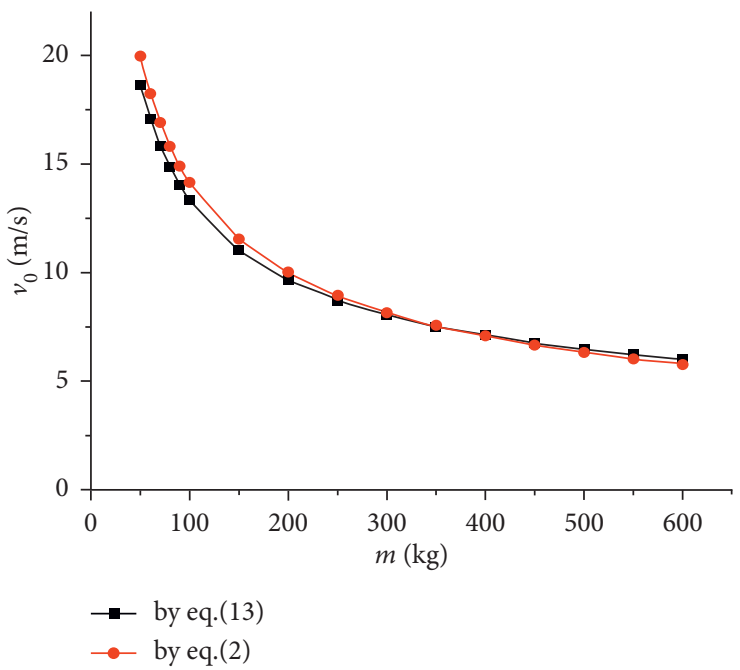

Figure 6: Theoretic curves of $v_{0}-m$.

\section{Experiments and Results}

An experimental system shown in Figure 7 was set up for further investigation into this technology.

A piezoelectric accelerometer (DL111-1P) with an acceleration range of $10000 \mathrm{~g}$ and a charge amplifier (CENOCERA YE5852) are used to sense the shock acceleration. The measurement and control system can complete the operation of the shock machine and the acquisition, analysis, and display of the shock acceleration signal.

Using the abovementioned experimental setup, some tests were conducted to verify the effectiveness. All tests were 


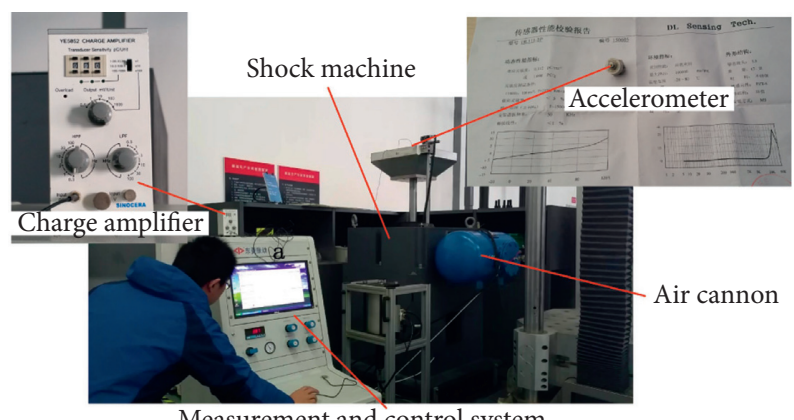

Figure 7: Experimental setup and test scenario.

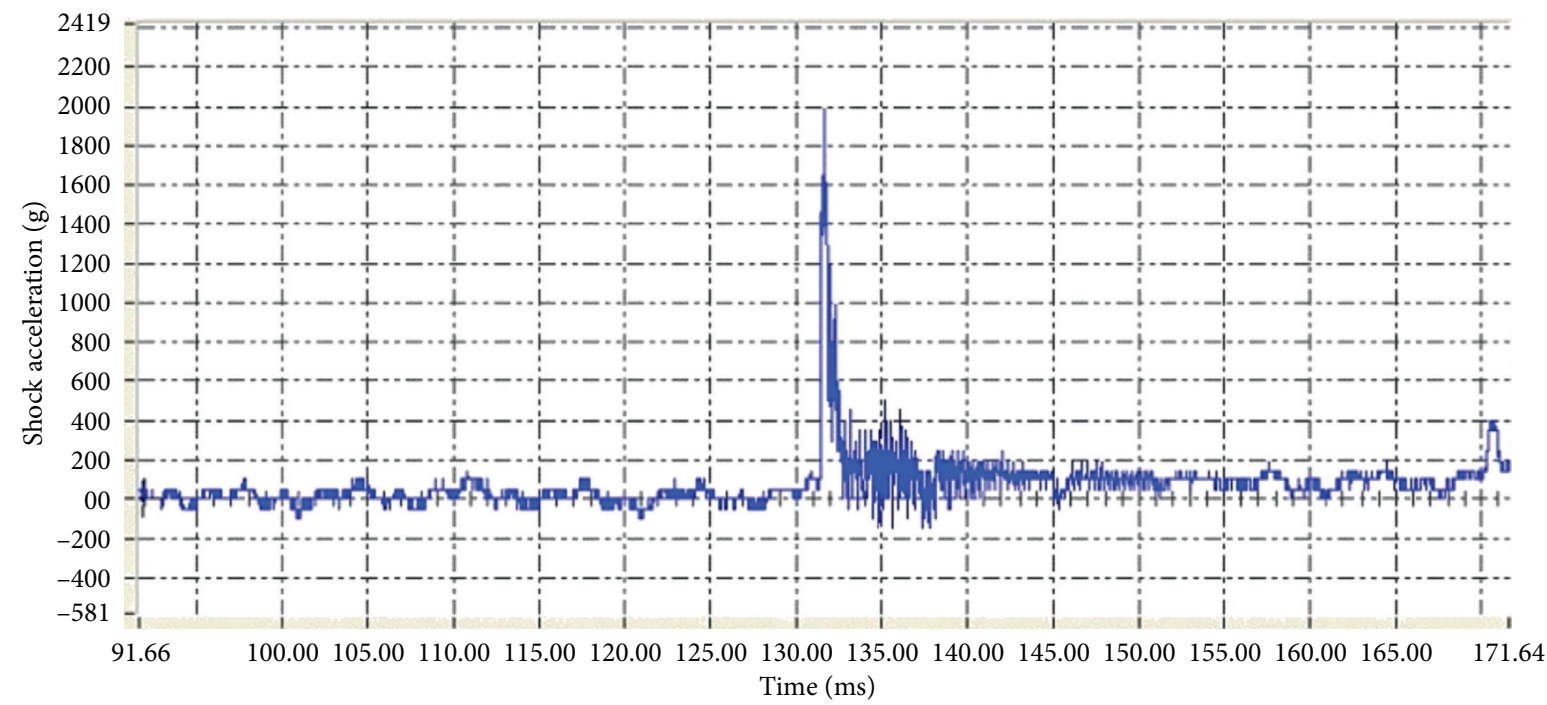

(a)

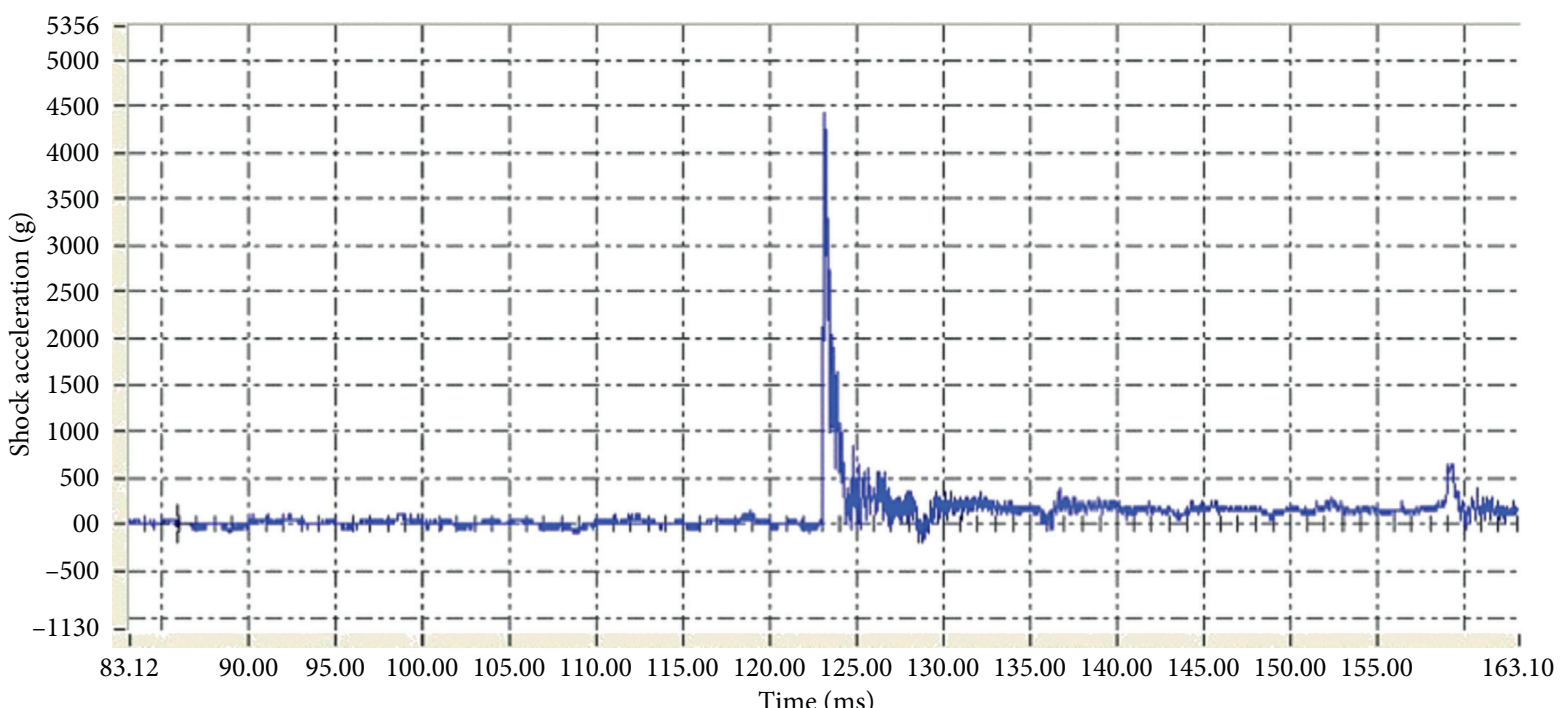

(b)

Figure 8: Typical test results with no payloads. Air cannon pressure is (a) $0.5 \mathrm{MPa}$ and (b) $0.65 \mathrm{MPa}$. 
executed with a piston stroke of $300 \mathrm{~mm}$, and no tested pieces, in addition, two annulus rubber pulse generators with a thickness of $10 \mathrm{~mm}$, were used to shape the shock acceleration pulse. Figure 8 shows the typical test results.

When the pressure of the air cannon is $0.5 \mathrm{MPa}$, a measured acceleration-time curve is shown in Figure 8(a). It can be seen that the shock peak acceleration is $1990 \mathrm{~g}$, and the pulse width is $1.26 \mathrm{~ms}$. Figure 8(b) shows the accelerationtime curve measured when the air cannon pressure is $0.65 \mathrm{Mpa}$. It is very encouraging that the shock peak acceleration is $4429 \mathrm{~g}$, and the pulse width is $1.20 \mathrm{~ms}$.

These shock pulses are similar to the shape of a half-sine. It is noted that the rising edges of the pulses are steep and smooth, but the falling edges are gradual and coupled with some high-frequency oscillations. This may be related to the material and structure of the pulse generators and the carriage. But it is not surprising, as this is a common case in high acceleration shock tests. Moreover, due to the use of an air cannon, the excitation energy is very large. Inevitably, some unwanted interference signals are more easily excited and then captured by the accelerometer.

It can also be seen from Figure 8 that some secondary acceleration peaks are found at about $170 \mathrm{~ms}$ and $159 \mathrm{~ms}$ in the shock acceleration-time curves, respectively. This may ascribe the secondary collision between the impact plate and the anvil.

However, the peak acceleration value of the secondary collision is much smaller than that of the main pulse, and the time interval between the second peak and the main one is more than 30 times of the pulse width. This will not affect the signal truncation of subsequent spectrum analysis or shock response spectrum analysis. Therefore, we do not need to pay too much attention to the secondary collision.

\section{Conclusion}

In the field of high-g shock experiments, the technology with large load capacity has always been concerned. This paper presents a technology which is especially suitable for this demand. A schematic diagram of the shock machine was proposed, and an idea gas mechanical model was established. Then, some theoretical analyses were described. According to the results of theoretical analysis, a prototype of shock machine was developed, and an experimental system was established. The verification tests were executed with a piston stroke of $300 \mathrm{~mm}$, and no tested pieces where two annulus rubber pulse generators with thickness of $10 \mathrm{~mm}$ were used to shape the shock acceleration pulse. The typical test results show that the shock accelerations are $1990 \mathrm{~g}$ and $4429 \mathrm{~g}$, the pulse widths, $1.26 \mathrm{~ms}$ and $1.20 \mathrm{~ms}$, for the air cannon pressure of $0.5 \mathrm{MPa}$ and $0.65 \mathrm{MPa}$.

The remarkable feature of this technology is that an air cannon was deliberately used as the excitation energy source of the shock machine. It infers that the processing requirements and cost of the shock machine can be greatly reduced. More importantly, the experiment indexes are greatly exciting, and it can be used in a wider range of high-g shock experiments by using an air cannon with a different volume, changing the pressure of the compressed air, using a different pulse generator, and setting different piston stroke.

In the following study, we will conduct more in-depth development of this technology, making it an effective means of the high-g shock experiment.

\section{Data Availability}

The data used to support the findings of this study are available from the corresponding author upon request.

\section{Conflicts of Interest}

The authors declare that they have no conflicts of interest.

\section{Acknowledgments}

This project was not only supported by the subproject of the National Key Research and Development Program of China (no. 2018YFB2001400) but also by the program for opening project of State Key Laboratory of Mechanical Transmission of Chongqing University (SKLMT-KFKT-201811) and the Program for Changjiang Scholars and Innovative Research Teams in the University of China (IRT1033).

\section{References}

[1] J. Xu, H. Chen, C. Tan, H. Chen, and G. Zhou, "Numerical and experimental investigations for an air cannon optimization," Science China Technological Sciences, vol. 54, no. 2, pp. 345351, 2011.

[2] NASA-STD-7003, Pyroshock Test Criteria, National Aeronautics and Space Administration, Washington, DC, USA, 1999.

[3] R. D. Sill, "Shock calibration of accelerometers at amplitudes to 100,000 g using compression waves," Endevco TP 283, San Juan Capis-trano, CA, USA, 1983.

[4] R. Stewart, R. Thede, P. Couch, and D. Tarrant, "High g MEMS accelerometer for compact kinetic energy missile (CKEM)," in Proceedings of the Posi-tion Location and Navigation Symposium, Monterey, CA, USA, April 2004.

[5] T. G. Brown, B. Davis, D. Hepner et al., "Strap-down microelectromechanical (MEMS) sensors for high-g munition applications," IEEE Transactions on Magnetics, vol. 37, no. 1, pp. 336-342, 2001.

[6] R. M. Schmidt and K. A. Holsapple, "Theory and experiments on centrifuge cratering," Journal of Geophysical Research: Solid Earth, vol. 85, no. B1, pp. 235-252, 1980.

[7] L. W. Burke Jr., E. S. Irwin, R. Faulstich, C. E. Newnham, and N. Scholey, "High-g power sources for the US Army's HSTSS programme," Journal of Power Sources, vol. 65, no. 1-2, pp. 263-270, 1997.

[8] R. O’Reilly, H. Tang, and W. Chen, "High-g testing of MEMS devices, and why," in Proceedings of the IEEE Sensors 2008 Conference, pp. 148-151, Lecce, Italy, October 2008.

[9] S. T. Jenq, H. S. Sheu, C.-L. Yeh, Y.-S. Lai, and J.-D. Wu, "High-G drop impact response and failure analysis of a chip packaged printed circuit board," International Journal of Impact Engineering, vol. 34, no. 10, pp. 1655-1667, 2007.

[10] H. Nozato, T. Usuda, A. Oota, and T. Ishigami, "Calibration of vibration pick-ups with laser interferometry: part IV. Development of a shock acceleration exciter and calibration 
system," Measurement Science and Technology, vol. 21, Article ID 065107, 2010.

[11] Z. Duan, Y. Zhao, and J. Liang, "A simply constructed but efficacious shock tester for high-g level shock simulation," Review of Scientific Instruments, vol. 83, no. 7, Article ID 075115, 2012.

[12] X. Zhang, Y. Zhao, Z. Duan, and X. Li, "A high-g shock tester with one-level velocity amplifier," Measurement Science \& Technology, vol. 24, no. 4, Article ID 045901, 2013.

[13] http://www.bench.com/EngineeringServices for Shock Mach ine $^{\circledR}$ Test Systems ${ }^{\circledR}$. 